\title{
A management strategy for the long-term conservation of the Endangered sand-dune lizard Liolaemus multimaculatus in the Pampean coastal dunes of Argentina
}

\author{
Federico P. Kacoliris, Melina A. Velasco, Camila Kass, Nicolas Kass \\ Verónica Simoy, Pablo G. Grilli, Tomas Martínez Aguirre \\ Diego O. Di Pietro, Jorge D. Williams and Igor Berkunsky
}

\begin{abstract}
The sand-dune lizard Liolaemus multimaculatus is an Endangered species endemic to the Pampean coastal dunes of Argentina. To inform the development of a future Action Plan for this species, we investigated the demography and conservation status of all remaining populations, and we suggest management actions appropriate to local needs. We used population viability analysis to assess extinction risk in three inbreeding scenarios and estimate the minimum viable population and the minimum area requirement. To assess the current status of each local population, we used information related to population size, human pressure and connectivity. The results were then used to set and prioritize conservation management actions at local level. Our models indicated that populations of $>2,400$ individuals would be viable in the long term and that inbreeding depression has a strong effect on extinction risk. The southern patches of coastal dune contain the largest populations of sand-dune lizards, and they are also better connected and less threatened. We suggest land protection as the priority management action for populations larger than the minimum viable population, whereas habitat recovery, when possible, should be the priority for patches of coastal dune smaller than the minimum area requirement. Supplementation with a small number of individuals could stabilize unviable populations but should be considered only in certain situations.

The long-term conservation of the sand-dune lizard will be feasible only if a conservation action plan is developed and implemented.
\end{abstract}

Federico P. Kacoliris (Corresponding author), Melina A. Velasco, Camila Kass, Nicolas Kass, Tomas Martínez Aguirre, Diego O. Di Pietro and Jorge D. Williams Sección Herpetología, División Zoología Vertebrados, Consejo Nacional de Investigaciones Científicas y Técnicas, Facultad de Ciencias Naturales y Museo, Universidad Nacional de La Plata, La Plata 1900, Argentina E-mail kacoliris@fcnym.unlp.edu.ar

Verónica Simoy and IgOR BERKUNSKy Instituto Multidisciplinario sobre Ecosistemas y Desarrollo Sustentable, Consejo Nacional de Investigaciones Científicas y Técnicas, Universidad Nacional del Centro de la Provincia de Buenos Aires, Tandil, Argentina

Pablo G. GRILli Cátedra de Ecología General y Recursos Naturales, Universidad Nacional Arturo Jauretche, Florencio Varela, Argentina

Received 26 October 2016. Revision requested 16 December 2016.

Accepted 18 May 2017. First published online 11 August 2017.
Keywords Coastal dune, Liolaemus multimaculatus, longterm viability, management actions, minimum area requirements, minimum viable population, population viability analysis, sand-dune lizard

\section{Introduction}

The sand-dune lizard Liolaemus multimaculatus is en-

demic to a narrow strip of coastal dunes in Buenos Aires and northern Río Negro provinces of Argentina (Cei, 1993), and is categorized as Endangered on the IUCN Red List (Kacoliris et al., 2016a). It is a habitat specialist, with anatomical, ecological and ethological adaptations for living in sandy grassland (Cei, 1993; Halloy et al., 1998). The sand-dune lizard is one of the most studied of the c. 250 species in the genus Liolaemus (Vega, 1999; Kacoliris, 2009).

The current range of the sand-dune lizard is severely fragmented, and these fragments are experiencing an ongoing decline in extent and quality (Abdala et al., 2012). Urban and forestry areas have replaced more than one quarter of the original habitat occupied by this species (Faggi et al., 2010; Isla, 2010), increasing the isolation of the remaining populations. These fragmented populations are also facing several other threats, such as the intense transit of off-road vehicles on dunes, invasive predators (e.g. wild boar Sus scrofa and several birds of prey), and road construction (Vega et al., 2000; Kacoliris et al., 2016a). All these threats are the main causes of the current population decline of this species.

Researchers and practitioners are concerned about the conservation status of the sand-dune lizard. However, current management actions are limited to isolated awarenessraising activities, and there is a lack of sound conservation management for the few populations inhabiting protected areas (Kacoliris et al., 2016b). Moreover, the lack of information about demographic trends of local populations makes it difficult to decide where to allocate management efforts. Because most of the habitat is in isolated fragments, it is important to determine the population status and extinction risk for each fragment. 
Population viability analysis, a reliable tool for modelling demography (Shaffer, 1981), can provide information about the vulnerability of local populations of sand-dune lizards and help to evaluate management options for the species' recovery (Bode \& Brennan, 2011; Peér et al., 2013). Although it has been used for demographic studies of the Swedish sand lizard Lacerta agilis (Berglind, 200o) and validated for the sagebrush lizard Sceloporus graciosus (Brook et al., 2000), population viability analysis has rarely been applied to the management of Neotropical reptiles, including the sand-dune lizard. A population viability analysis of this species will facilitate estimation of the minimum number of individuals that a population needs to be viable in the long term (i.e. the minimum viable population) and the minimum area needed to support the minimum viable population (i.e. the minimum area requirement).

Here we (1) assess the minimum viable population and the minimum area requirement for the sand-dune lizard; (2) evaluate the status of all remaining populations inhabiting Pampean coastal dunes; and (3) suggest and prioritize several management actions to improve the conservation of each local population. Our results will facilitate the design of a management strategy to ensure the long-term conservation of all remaining populations of the sand-dune lizard.

\section{Study area}

The Pampean coastal dunes of Argentina are one of the last remains of coastal Pampa in South America (Cabrera, 1976) and encompass $80 \%$ of the range of the sand-dune lizard (Kacoliris, 2009). The dunes comprise several habitats, including dune grassland (the habitat of the sand-dune lizard), beach, wetland, and urban and forestry areas (Faggi et al., 2010; Isla, 2010). The mountain system of Tandilia divides the coastal dunes into two regions: the oriental and austral dunes (Isla \& Lasta, 2006) (Fig. 1).

\section{Methods}

\section{Minimum viable population and minimum area requirement}

We estimated the minimum viable population by developing a population viability analysis to test the extinction risk of each local population of the sand-dune lizard. We developed models using Vortex 10.1.5.o, an individual-based simulation that considers deterministic forces and demographic, environmental and genetic stochastic events (Lacy et al., 2009), which has been proven to yield accurate results when reliable data are used (Brook et al., 200o). We used baseline data from populations of sand-dune lizards inhabiting oriental and austral dune regions, including age at first reproduction ( 2 years, E. Kubish, pers. comm.), reproductive system and reproductive rates (Vega, 1997, 1999; Kacoliris, 2009), lifespan (6 years, E. Kubish, pers. comm.), population structure (Kacoliris, 2009), annual survival (Kacoliris et al., 2013), and population size. We used the $95 \%$ upper confidence interval of known density for this species (i.e. 10 individuals per ha) to calculate the population size. Density estimations were obtained from two populations of sand-dune lizards inhabiting oriental dunes and two populations inhabiting austral dunes (Kacoliris, 2009; Kacoliris et al., 2009a; F. P. Kacoliris, unpubl. data).

Considering that inbreeding depression may affect extinction risk in wild populations (Brook et al., 2002; Frankham et al., 2002), we decided to include this variable in population viability analysis models. However, because of the lack of information about inbreeding depression in the sand-dune lizard (and for lizards in general), we modelled three scenarios: (1) no inbreeding: no diploid lethal equivalents; (2) conservative inbreeding (6.29 total diploid lethal equivalents): the default value set in Vortex 10.1.5.o (Lacy et al., 2009); and (3) realistic inbreeding (12 total diploid lethal equivalents): the value most likely to occur in wild populations of vertebrates (O'Grady et al., 2006). We used these scenarios to assess the effect of inbreeding on extinction risk, but we based the minimum viable population estimates on the third scenario.

We considered the following assumptions in the population viability analysis. (1) Populations are at carrying capacity (i.e. initial abundances were considered to be equal to the carrying capacity). This assumption is supported by the absence of geographical and time variability in density estimations for the sand-dune lizard. (2) Forty generations of the sand-dune lizard (i.e. c. 250 years) represent an adequate time-frame to assess viability, overcoming long-term patterns of demographic decline (Frankham et al., 2014). (3) Populations are isolated, (we wanted to evaluate their longterm viability in the absence of connectivity; i.e. at patch scale). (4) Climatic catastrophes do not significantly affect the viability of the sand-dune lizard. This latter assumption is based on the absence of extreme meteorological phenomena (e.g. strong storms or winds, droughts) reported for coastal dunes during the past 50 years (SMN, 2016).

To establish the minimum viable population we simulated population dynamics 1,000 times over 250 years, starting from 100 individuals and successively increasing by 100 individuals each time, until a stable population was reached (i.e. the probability of extinction $\mathrm{PE}_{250}$ years $\leq$ o.01). Thereafter, we calculated the minimum area requirement by dividing the minimum viable population obtained by the $95 \%$ upper confidence interval of known density for this species.

\section{Current status of populations}

To assess population status, firstly we recorded suitable and unsuitable areas for the sand-dune lizard throughout its 

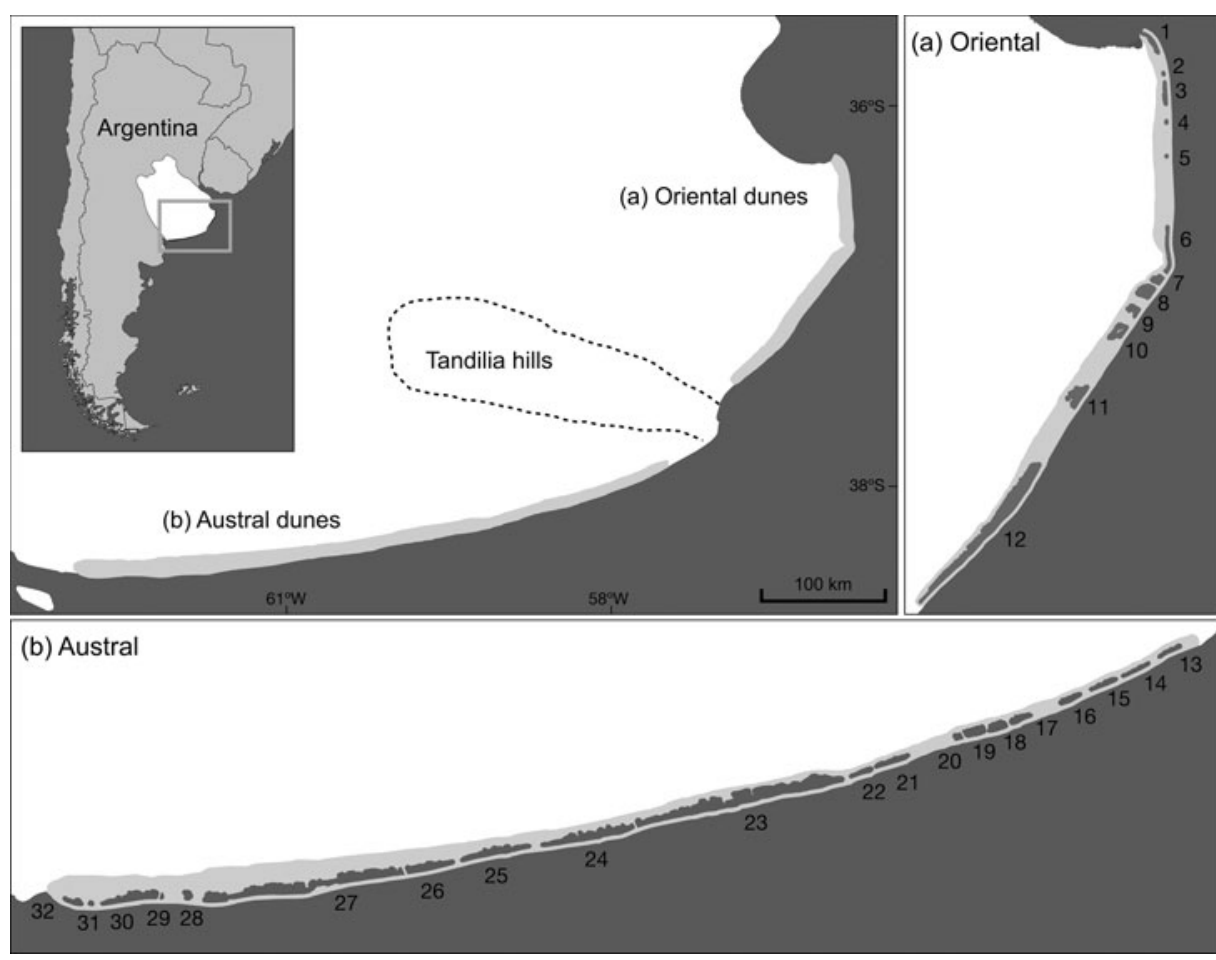

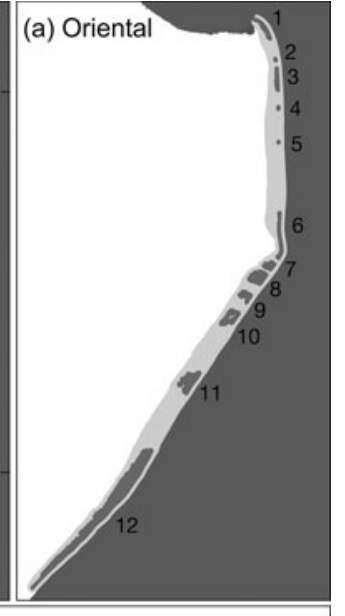

FIg. 1 The (a) oriental and (b) austral regions of the Pampean coastal dunes of Argentina, which are home to the sand-dune lizard Liolaemus multimaculatus and are separated by the Tandilia mountain system. Current patches of suitable habitat for the species are shaded dark grey (see Table 2 for details). whole range in the Pampean coastal dunes. Based on available information about the sand-dune lizard's spatial ecology and habitat preferences (Kacoliris et al., 2009b, 2010, 2011; Stellatelli et al., 2015a,b) we defined a suitable area as a continuous portion of coastal dune containing habitat used by the species, and an unsuitable area as a portion of coastal dune where the original habitat was almost entirely replaced by urban and/or forestry areas. We delimited suitable and unsuitable areas by drawing polygons on QuickBird satellite imagery (spatial resolution up to $0.6 \mathrm{~m}$; Satellite Imaging Corporation, Houston, Texas). Within the suitable areas we also differentiated between patches and corridors.

We defined a patch as a portion of coastal dune that had not undergone significant changes in relation to the original habitat, and with representativeness of three dune types (ecotone grassland, interdune and frontal dune) related to a healthy ecosystem (Kacoliris et al., 2009b). We defined a corridor as a portion of coastal dune positioned between two patches and lacking one or more of the three dune types (they are usually formed by a frontal dune between an urban area and the ocean). Corridors are highly disturbed, and therefore we assumed they had a low probability of supporting a viable population of sand-dune lizards, but they are more permeable to dispersal than unsuitable areas. For most patches we were able to use field data collected during 2001-2016 to validate the existence of suitable habitat and to verify the occurrence of lizards.

To assess quantitatively the status of sand-dune lizard populations inhabiting each patch of dune, we applied a modification of the method developed by Kacoliris et al. (2016a). This method aims to identify management actions for area-based units according to three metrics: conservation value, habitat availability and human pressure. In this case we considered population size as the conservation value metric, connectivity instead of habitat availability (because availability of habitat is included in the population size metric), and conservation status as the human pressure metric.

We calculated the population size metric for each patch by multiplying the area of the patch by a density of 10 lizards per ha (i.e. the $95 \%$ upper confidence interval of the known density for the species). Patches with a population larger than the minimum viable population (or an area larger than the minimum area requirement) would support a viable population of sand-dune lizards, even under isolation conditions. However, patches with a population smaller than the minimum viable population would be unviable in the long term.

Landscape connectivity plays an essential role in the dispersal of organisms (Tischendorf \& Fahrig, 2000). To estimate the connectivity metric, we applied a modification of the functional linkage index (Lin, 2009). This index yields a higher value of connectivity for a specific patch when neighbouring patches are larger and when the distance to these patches is smaller.

We defined the conservation status metric for each patch as the combined effect of human pressure and patch shape. We estimated human pressure as the logarithm of the total number of residents and tourists immediately surrounding each patch (Edwin, 2012), and patch shape as the ratio of area over perimeter. The conservation status of each patch 
was calculated as the ratio of human pressure over shape (i.e. higher values reflect a worse conservation status). Patch shape is related to edge effect and has implications for interior species sensitive to patch shape and for ecosystem integrity (Laurance \& Yensen, 1991; Forman, 1995). Despite the paucity of studies of the sand-dune lizard, we assumed an effect of patch shape on this species, considering that most of the threats (i.e. exotic predators, woody invasive species, and off-road traffic) are more intense along patch borders.

To facilitate comparison we standardized the three metrics as follows: (value of the metric for the patch - mean of the metric) / standard deviation. To facilitate the interpretation of metrics, we multiplied the conservation status metric by -1 . Positive values indicated desirable scenarios in conservation terms and we were able to compare metrics among patches, categorically (positive and negative status) and in magnitude (how far from zero), by ranking them from worst to best scenarios.

\section{Management actions}

We recognized five types of management actions (IUCN-CMP, 2006) that could be applied to improve the conservation of the sand-dune lizard: (1) land protection, (2) habitat recovery, (3) supplementation of individuals, (4) enhancement of corridors, and (5) reduction of threats. Based on the value of the metrics, and considering the minimum viable population, we suggested management actions for each patch: land protection for patches with populations larger than the minimum viable population; habitat recovery (or the percentage of area needed to reach minimum area requirement) and supplementation of individuals for patches with populations smaller than the minimum viable population; enhancement of corridors for patches with a negative value of the connectivity metric; and reduction of threats for patches with a negative value of the conservation status metric.

In those patches where more than one management action was needed we categorized actions as high, medium or low priority. We also included the category unviable for cases in which it would not be possible to carry out the required management action. We focused prioritization on protecting populations larger than the minimum viable population and increasing the size of populations smaller than the minimum viable population, proposing the following prioritization criteria: in patches with populations larger than the minimum viable population, land protection is always recommended to be a high priority (in agreement with Dixo \& Metzger, 2009); in patches with populations smaller than the minimum viable population and where habitat recovery is possible, it is recommended that habitat recovery is a high priority, followed by supplementation of individuals (medium priority) and reduction of threats/enhancement of
TABLE 1 Minimum viable population, minimum area requirement, stochastic population growth rate ( $\mathrm{r}$ ), and simulated mean population size at the end of 250 years ( $\mathrm{N}$-extant), for three inbreeding scenarios (see text for details) of the sand-dune lizard Liolaemus multimaculatus, endemic to a narrow strip of coastal dune in Argentina (Fig. 1).

\begin{tabular}{llll}
\hline & $\begin{array}{l}\text { No in- } \\
\text { breeding }\end{array}$ & $\begin{array}{l}\text { Conservative } \\
\text { inbreeding }\end{array}$ & $\begin{array}{l}\text { Realistic } \\
\text { inbreeding }\end{array}$ \\
\hline $\begin{array}{l}\text { Minimum viable } \\
\text { population }\end{array}$ & 190 & 1,400 & 2,400 \\
$\begin{array}{l}\text { Minimum area } \\
\text { requirement (ha) }\end{array}$ & 19 & 140 & 240 \\
$\begin{array}{l}\text { r } \pm \text { SD } \\
\text { N-extant } \pm \text { SD }\end{array}$ & $0.04 \pm 0.13$ & $0.03 \pm 0.12$ & $0.02 \pm 0.11$ \\
\hline
\end{tabular}

corridors (low priority); in patches with populations smaller than the minimum viable population and where habitat recovery is unviable (e.g. in cases where the patch is adjacent to an urban centre), supplementation of individuals is recommended to be a high priority, and reduction of threats/enhancement of corridors a medium priority (in the case of negative values of metrics) or low priority (in the case of positive values); no priority was set between reduction of threats and enhancement of corridors when both metrics were either negative or positive, because these metrics are not comparable in terms of population viability.

To recommend the minimum number of adult pairs (a male and a female) of sand-dune lizards that should be supplemented into each patch of dune where this action is suggested, we developed population viability analysis models under the same assumptions considered above. We ran a set of models for six initial population sizes smaller than the minimum viable population $(100,200,300,500,1,000$ and 1,500 individuals), and for four release strategies based on the frequency of releases (every 1, 3, 5 or 10 years). In each case we recorded the number of individuals that must be released to obtain a viable population (i.e. $\mathrm{PE}_{250}$ years $\leq 0.01$ ).

\section{Results}

\section{Minimum viable population and minimum area requirements}

Deterministic projections associated with the population dynamics of the sand-dune lizard showed an exponential rate of increase (r) of 0.05 , a rate of annual change $(\lambda)$ of 1.05 , a rate of change between generations $\left(R_{\mathrm{o}}\right)$ of 1.22, a generation time of 3.99 years for females and 3.66 years for males, and a sex ratio (males to females) of 0.40 .

Estimations of the minimum viable population for each inbreeding scenario, as well as other important viability measures highlighted by Peér et al. (2013) are summarized in Table 1. Inbreeding depression has an important effect 


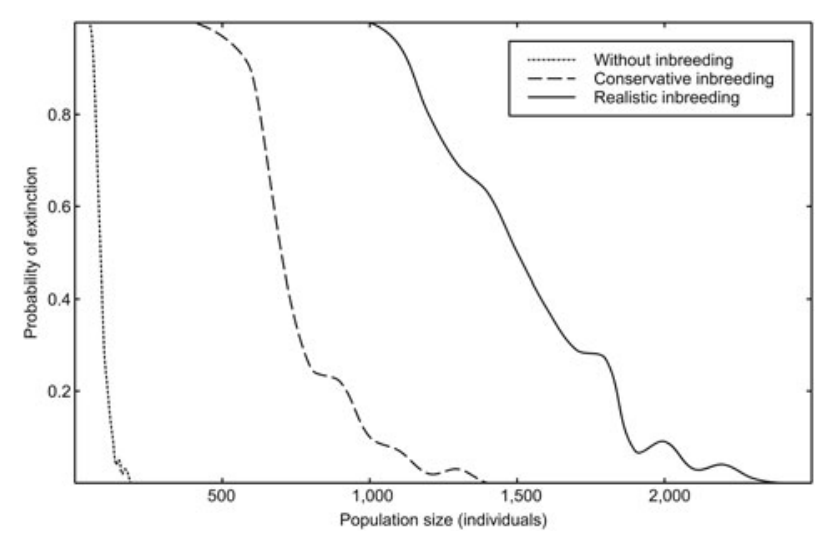

FIG. 2 Probability of extinction ( $\mathrm{PE}_{250}$ years $)$ of the sand-dune lizard, as a function of population size, for three scenarios of inbreeding depression.

on the extinction risk of the sand-dune lizard. A realistic value of 12 total diploid lethal equivalents increased the minimum viable population 13 -fold over estimations obtained from non-inbreeding models (Fig. 2).

\section{Conservation status of populations}

We confirmed the presence of lizards at $84 \%$ of the 32 identified patches (patches 1, 3, 6-12, 15-19 and 21-30; Fig. 1) and the occurrence of suitable habitat in all patches. We detected few lizards in the area connecting patches 4 and 5, indicating that this area may act as a corridor (Fig. 1).

Under the assumptions considered herein at least $40 \%$ of populations of the sand-dune lizard inhabiting the 32 patches of coastal dune would be unviable in isolation; the remaining $60 \%$ may be viable in the long term. The austral dune region hosts 11 of the 19 largest populations of this species, and most of these patches are among the best connected and least threatened (Fig. 3a,b).

\section{Management actions}

The values of the three metrics as well as proposed management actions for each patch are summarized and ranked in Table 2 . The priority patch for land protection was 23 , followed by 12 and 27 (Fig. 1). Although habitat recovery should be considered for the 13 patches with sand-dune lizard populations smaller than the minimum viable population, this action would be viable only at nine of these patches (Table 2), as patches 2, 4, 5 and 31 are adjacent to cities.

Supplementation with few individuals can promote the long-term viability of populations smaller than the minimum viable population. Populations with $>100$ individuals can be stabilized by adding a pair of individuals, if supplementation is made every year, to 18 individuals ( 9 males and 9 females), if supplementation is made every 10 years. In the case of populations of 1,500 individuals, supplementation with a pair of lizards every year or with eight lizards ( 4 males and 4 females) every 10 years is enough to attain long-term viability (Fig. 4).

\section{Discussion}

We assessed for the first time the dynamics and extinction risk of all remaining populations of the sand-dune lizard inhabiting the Pampean coastal dunes, and recommend conservation management actions for each habitat patch, based on population size, connectivity and conservation status. Our results provide an updated diagnostic of conservation status and could be used for rapid identification of conservation needs for each local population. This information will serve as a basis for the development of the first conservation strategy, to be included in an Action Plan to ensure longterm viability of the sand-dune lizard.

As most of our results were based on the estimation of the minimum viable population through population viability analysis, the limitations of this approach should be taken into consideration. For example, Reed et al. (2002) argue that minimum critical sizes are sensitive to small errors in demographic data, and models are not accurate enough to make precise predictions. However, Reed et al. (2002) also state that population viability analysis is one of the most powerful and pervasive tools in conservation biology. We agree with Reed et al. (2003) that any estimation of extinction risk is a de facto estimation of the minimum viable population and that estimation of the minimum viable population through population viability analysis could have significant heuristic value, leading to scientifically defensible generalizations concerning viable populations. Although we find our results to be of utility, we are aware of the limitations related to modelling, and thus we recommend that managers consider our results with caution when developing an Action Plan for the sand-dune lizard.

More than half (19 of 32 ) of the current patches of coastal dune are large enough to support viable populations of sand-dune lizards in isolation. These populations are of key importance for the viability of the species as long as no major changes occur in the future. However, considering the current real-estate value of coastal land properties, a continued and severe process of habitat fragmentation is likely, particularly given the increase in urbanization and the lack of regulations for high-impact activities. During the 20 th century more than $25 \%$ of the coastal dunes was lost, and urban development is ongoing, without any regional planning, leading to further habitat loss and a decline in lizard populations (Vega et al., 2000; Kacoliris et al., 2016a). In this scenario it is not possible to ensure the longterm viability of the sand-dune lizard (even considering the existence of large populations) without the development of management actions framed within a conservation strategy. 

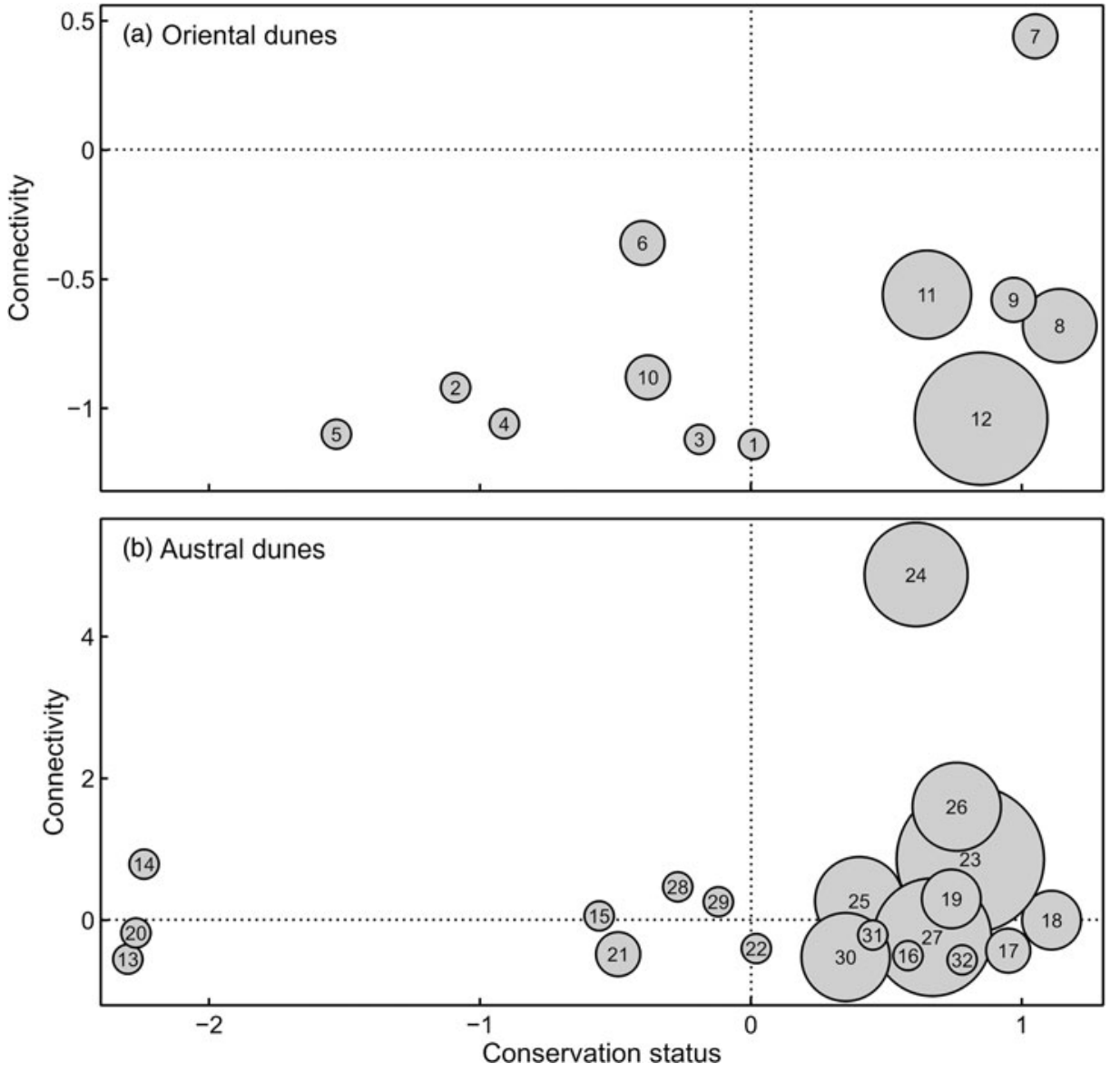

FIG. 3 Connectivity and conservation status metrics (negative values represent the worst situations) for patches of (a) oriental and (b) austral dunes in the Pampean coastal region of Argentina (Fig. 1). Circle size is proportional to sand-dune lizard population size (which is equivalent to patch area). For references to patch numbers see Fig. 1 and Table 2.
Among the management actions identified, we defined land protection as a priority as we believe that the conservation of the sand-dune lizard will depend predominantly on the maintenance of continuous tracts of coastal dune inhabited by large populations of the species. This is in agreement with the observations made by Dixo \& Metzger (2009) for other lizard species. According to this reasoning, populations smaller than the minimum viable population should firstly be managed to attain a viable situation (e.g. through habitat recovery and/or supplementation of individuals), at which point land protection should be promoted as the next step. When land protection is not possible, a strong awareness-raising campaign and the strengthening of current policies should be promoted in addition to other lowerpriority management actions.

Enhancement of corridors could be achieved through appropriate management of dune and beach. Although almost all current corridors are beach resorts, there are still some options to increase their permeability and improve connectivity between populations of sand-dune lizards. These include the use of structures for sand accumulation, restoration of native habitats, and removal of exotic vegetation (Stellatelli et al., 2013), and some have already been applied successfully at a local level (FPK, pers. obs.); for example, in Monte Hermoso city in the austral region (located between patches 28 and 29), a wooden raised walkway was constructed, facilitating sand accumulation and alleviating erosion of the beach. In contrast, the main street on the beachfront of Villa Gesell city in the oriental region (located between patches 11 and 12) was removed to extend the beach for tourism purposes. However, a similar management approach could be implemented there for conservation purposes, promoting the restoration of original dunes.

For areas smaller than minimum area requirement, habitat recovery could be an appropriate option. However, this action would work only for patches surrounded by forestry areas, where it would be possible to recover the habitat by removing exotic trees and introducing native grassland vegetation. An alternative for patches where this action is unviable (i.e. those in urban areas) could be to increase the carrying capacity by increasing the availability of the species' preferred microhabitats (Kacoliris, 2009; Stellatelli et al., 2013, 2015a). However, it is difficult to know whether this action could really facilitate a high density of individuals, or to what extent it could affect habitat dynamics. Controlled experiments are required to assess the feasibility of this kind of management.

Our simulations showed that unviable populations of sand-dune lizards could be made viable by supplementing them with a few pairs of lizards each year. Supplementation 
TABLE 2 Population size and required management actions (prioritized as High, Medium, Low or Unviable) for the sand-dune lizard in all patches of Pampean coastal dune occupied by the species (Fig. 1).

\begin{tabular}{|c|c|c|c|c|c|c|}
\hline \multirow[b]{2}{*}{ Dune patch } & \multirow[b]{2}{*}{ Population size } & \multicolumn{5}{|c|}{ Management actions } \\
\hline & & $\begin{array}{l}\text { Land } \\
\text { protection }\end{array}$ & $\begin{array}{l}\text { Habitat recovery } \\
\text { (ha to be } \\
\text { recovered) }\end{array}$ & Supplementation & $\begin{array}{l}\text { Reduction of } \\
\text { threats (Conservation } \\
\text { status metric) }\end{array}$ & $\begin{array}{l}\text { Enhancement of } \\
\text { corridors } \\
\text { (Connectivity metric) }\end{array}$ \\
\hline 1 & 3,225 & High & & & Low $(0.01)$ & Medium $(-0.57)$ \\
\hline 2 & 170 & & Unviable & High & Medium (-1.09) & Medium $(-0.46)$ \\
\hline 3 & 2,338 & & High (6) & Medium & Low $(-0.19)$ & Low $(-0.56)$ \\
\hline 4 & 210 & & Unviable & High & Medium $(-0.91)$ & Medium $(-0.53)$ \\
\hline 5 & 140 & & Unviable & High & Medium $(-1.53)$ & Medium $(-0.55)$ \\
\hline 6 & 3,741 & High & & & Low $(-0.40)$ & Medium $(-0.18)$ \\
\hline 7 & 4,146 & High & & & Low (1.05) & Low $(0.22)$ \\
\hline 8 & 11,326 & High & & & Low (1.14) & Medium $(-0.34)$ \\
\hline 9 & 4,227 & High & & & Low $(0.97)$ & Medium $(-0.29)$ \\
\hline 10 & 5,725 & High & & & Low $(-0.38)$ & Medium $(-0.44)$ \\
\hline 11 & 13,284 & High & & & Low $(0.65)$ & Medium $(-0.28)$ \\
\hline 12 & 82,318 & High & & & Low $(0.85)$ & Medium $(-0.52)$ \\
\hline 13 & 1,180 & & High (122) & Medium & Low $(-2.30)$ & Low $(-0.55)$ \\
\hline 14 & 942 & & High (146) & Medium & Low $(-2.24)$ & Low $(0.79)$ \\
\hline 15 & 2,250 & & High (15) & Medium & Low $(-0.56)$ & Low $(0.06)$ \\
\hline 16 & 3,360 & High & & & Low $(0.58)$ & Medium $(-0.50)$ \\
\hline 17 & 4,050 & High & & & Low $(0.80)$ & Medium $(-0.33)$ \\
\hline 18 & 6,269 & High & & & Low $(0.91)$ & Low $(0.00)$ \\
\hline 19 & 8,326 & High & & & Low $(0.74)$ & Medium $(-0.20)$ \\
\hline 20 & 917 & & High (148) & Medium & Low $(-2.27)$ & Low $(-0.18)$ \\
\hline 21 & 3,950 & High & & & Medium $(-0.49)$ & Medium $(-0.48)$ \\
\hline 22 & 2,060 & & High (34) & Medium & Low $(0.02)$ & Low $(-0.40)$ \\
\hline 23 & 100,380 & High & & & Low $(0.81)$ & Low $(0.76)$ \\
\hline 24 & 25,480 & High & & & Low $(0.61)$ & Low (4.87) \\
\hline 25 & 13,820 & High & & & Low $(0.50)$ & Low $(0.17)$ \\
\hline 26 & 14,330 & High & & & Low $(0.76)$ & Low (1.30) \\
\hline 27 & 75,350 & High & & & Low $(0.67)$ & Medium $(-0.24)$ \\
\hline 28 & 2,020 & & High (38) & Medium & Low $(-0.27)$ & Low $(0.47)$ \\
\hline 29 & 624 & & High (178) & Medium & Low $(-0.12)$ & Low $(0.26)$ \\
\hline 30 & 13,720 & High & & & Low (0.35) & Medium $(-0.52)$ \\
\hline 31 & 350 & & Unviable & High & Low $(0.65)$ & Medium $(-0.21)$ \\
\hline 32 & 1,940 & & High (146) & & Low $(0.68)$ & Medium $(-0.56)$ \\
\hline
\end{tabular}

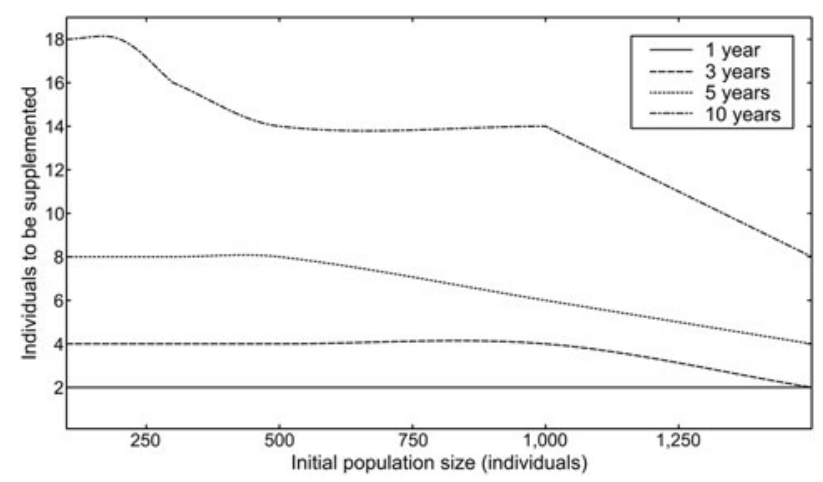

FIG. 4 Protocol to implement supplementation of individuals in habitat patches with sand-dune lizard populations smaller than the minimum viable population. The lines represent the thresholds of minimum number of individuals to be supplemented to achieve a viable population in relation to the initial population size. The line type identifies the time frame for reintroductions. could be done by translocating individuals from larger neighbouring populations or from an ex situ breeding programme (e.g. Corbett, 1969). The main problem with a supplementation programme in patches where populations are smaller than the minimum viable population is that supplementation should be performed continuously, and thus these populations would be dependent on conservation interventions in the absence of habitat recovery. For this reason we recommend habitat recovery as a priority over supplementation of individuals. In any case, supplementation should be considered only in very specific situations and developed under strict management protocols (IUCN/SSC, 2013).

There is agreement among specialists that the conservation status of the sand-dune lizard is declining (Kacoliris et al., 2016a). Many small populations are on the edge of extinction and the existence of current large patches of coastal dune are not a guarantee of the long-term survival of the species. Although we propose several management actions 
to protect the species and its habitat, these actions have yet to be tested. An adaptive management approach should be developed to simultaneously test the usefulness and feasibility of the actions suggested and address the urgent needs of the species. The long-term conservation of the sand-dune lizard will be feasible only if a conservation action plan is developed and implemented.

\section{Acknowledgements}

We thank R. Cañete, F. Tuñon, M. Buzato, J. Mangiarotti, A. Molinari, A. Rafael, G. Sánchez-Béliz, G. Guaitoli, C. Cassino, E. Guerrero, C. Ruiz de Arcaute, E. Kubish, B. Barret and F. Cunninghame for their help during field work. We also thank M. Caviglia for translation of this manuscript and valuable suggestions. Two anonymous reviewers and the Editor made valuable suggestions that significantly improved this article. This study was supported by the National Scientific and Technical Research Council of Argentina (CONICET; PIP-11220110100358, PIP-11220150100598), Agencia Nacional de Promoción Científica y Tecnológica (FONCYT 2012-0921), the Rufford Small Grants Foundation, the International Reptile Conservation Foundation and the Neotropical Grassland Conservancy. Dirección de Áreas Protegidas de la Provincia de Buenos Aires helped us with logistics and granted us the necessary permits for working in the field. Animal capture and handling techniques throughout the study followed the highest standards of animal welfare.

\section{Author contributions}

FPK, MAV and IB designed the study and wrote the article. CK, NK and VS built and ran the population viability analysis models. TM and DOD developed the spatial analysis. PGG and JDW helped to assess the management actions.

\section{References}

Abdala, C.S., Acosta, J.L., Acosta, J.C., Alvarez, B. Alberto-Rafael, F., Avila, L. et al. (2012) Categorización del estado de conservación de los lagartos de la República Argentina. Cuadernos de Herpetología, 26, 215-248.

BERGLIND, S.Å. (200o) Demography and management of relict sand lizard Lacerta agilis populations on the edge of extinction. Ecological Bulletins, 48, 123-142.

BODE, M. \& BRENNAN, K.E.C. (2011) Using population viability analysis to guide research and conservation actions for Australia's threatened malleefowl Leipoa ocellata. Oryx, 45, 513-521.

Brook, B.W., O'Grady, J.J., Chapman, A.P., Burgman, M.A., AкÇакауA, H.R. \& Frankham, R. (200o) Predictive accuracy of population viability analysis in conservation biology. Nature, 404, $385-387$.
Brook, B.W., Tonkyn, D.W., O'Grady, J.J. \& Frankham, R. (2002) Contribution of inbreeding to extinction risk in threatened species. Conservation Ecology, 6, 16, http://www.consecol.org/vol6/iss1/art16/.

Cabrera, A.L. (1976) Regiones Fitogeográficas Argentinas. Editorial ACME, Buenos Aires, Argentina.

Cei, J.M. (1993) Reptiles del Noroeste, Noreste y Este de la Argentina. Herpetofauna de las Selvas Subtropicales, Puna y Pampas. Museo Regionale di Scienze Naturali, Torino, Italia.

Corbett, K. (1969) Red light for the sand lizard in Britain. Oryx, 10, 89-90.

Dixo, M. \& Metzger, J.P. (2009) Are corridors, fragment size and forest structure important for the conservation of leaf-litter lizards in a fragmented landscape? Oryx, 43, 435-442.

Edwin, A.M. (2012) Censo nacional de población, hogares y viviendas 2010: censo del Bicentenario, resultados definitivos. Serie B no. 2. 1 st edition. INDEC, Buenos Aires, Argentina.

Faggi, A., Perepelizin, P. \& Dadon, J.R. (2010) South Atlantic tourist resorts: predictors for changes induced by afforestation. In Urban Biodiversity and Design (eds N. Müller, P. Werner \& J.G. Kelcey), pp. 363-378. Wiley-Blackwell, Oxford, UK.

Forman, R.T.T. (1995) Land Mosaics: The Ecology of Landscapes and Regions. Cambridge University Press, Cambridge, UK.

Frankham, R., Ballou, J.D. \& Briscoe, D.A. (2002). Introduction to Conservation Genetics. Cambridge University Press, Cambridge, UK.

Frankham, R., Bradshaw, C.J.A. \& Brook, B.W. (2014) Genetics in conservation management: revised recommendations for the 50/500 rules, Red List criteria and population viability analyses. Biological Conservation, 170, 56-63.

Halloy, M., Etheridge, R. \& Burghardt, G.M. (1998) To bury in sand: phylogenetic relationships among lizard species of the Boulengeri group, Liolaemus (Reptilia: Squamata: Tropiduridae), based on behavioral characters. Herpetological Monographs, 12, 1-37.

Isla, F. \& Lasta, C. (2006) Manual de manejo costero para la provincia de Buenos Aires. EUDEM, Mar del Plata, Argentina.

IsLA, F.I. (2010) Introducción al manejo de BarrerasMedanosas. In Manual de Manejo de Barreras Medanosas para la Provincia de Buenos Aires (eds F.I. Isla \& C.A. Lasta), pp. 7-26. EUDEM, Mar del Plata, Argentina.

IUCN-CMP (2006) Unified Classification of Conservation Actions, Version 1.o. IUCN, Gland, Switzerland.

IUCN/SSC (2013) Guidelines for Reintroductions and Other Conservation Translocations. Version 1.o. IUCN Species Survival Commission, Gland, Switzerland.

Kacoliris, F., Vega, L., Fitzgerald, L. \& Block, C. (2016a) Liolaemus multimaculatus. In The IUCN Red List of Threatened Species 2016: e.T56077628A56077635. Http://dx.doi.org/10.2305/IUCN. UK.2016-1.RLTS.T56077628A56077635.en [accessed 15 July 2016].

Kacoliris, F., Williams, J. \& Molinari, A. (2010) Selection of key features of vegetation and escape behavior in the sand dune lizard (Liolaemus multimaculatus). Animal Biology, $60,157-167$.

Kacoliris, F.P. (2009) Ecologíaespacial y dinámicapoblacional de la Lagartija de las Dunas (Liolaemus multimaculatus, Iguania, Liolamidae), en la Provincia de Buenos Aires. PhD thesis. Universidad Nacional de La Plata, La Plata, Argentina.

Kacoliris, F.P., Berkunsky, I. \& Velasco, M.A. (2013) Sex and size affect annual survival in a threatened Argentinean sand dune lizard. Herpetological Journal, 23, 59-62.

Kacoliris, F.P., Berkunsky, I. \& Williams, J.D. (2009a) Methods for assessing population size in sand dune lizards (Liolaemus multimaculatus). Herpetologica, 65, 219-226.

Kacoliris, F.P., Celsi, C.E. \& Monserrat, A.L. (2009b) Microhabitat use by the sand dune lizard Liolaemus multimaculatus: 
Liolaemidae in a Pampean coastal area in Argentina. Herpetological Journal, 19, 61-67.

Kacoliris, F.P., Velasco, M.A., Berkunsky, I., Celsi, C.E., Williams, J.D., Di-Pietro, D. \& Rosset, S. (2016b) How to prioritize allocating conservation efforts: an alternative method tested with imperilled herpetofauna. Animal Conservation, 19, 46-52.

Kacoliris, F.P., Williams, J.D., Quiroga, S., Molinari, A. \& Vicente, N. (2011) Ampliación del conocimiento sobre uso de hábitat en Liolaemus multimaculatus, sitios de fuga. Cuadernos de Herpetología, 25, 5-10.

Lacy, R.C., Borbat, M. \& Pollak, J.P. (2009) Vortex: A Stochastic Simulation of the Extinction Process, Version 9.95. Chicago Zoological Society, Brookfield, USA.

Laurance, W.F. \& Yensen, E. (1991) Predicting the impacts of edge effects in fragmented habitats. Biological Conservation, 55, 77-92.

Lin, J.P. (2009) The functional linkage index: a metric for measuring connectivity among habitat patches using least-cost distances. Journal of Conservation Planning, 5, 28-37.

O'Grady, J.J., Brook, B.W., Reed, D.H., Ballou, J.D., Tonkyn, D. W. \& FrAnKHAM, R. (2006) Realistic levels of inbreeding depression strongly affect extinction risk in wild populations. Biological Conservation, 133, 42-51.

Peér, G., Matsinos, Y.G., Johst, K., Franz, K.W., Turlure, C., RADCHUK, V. et al. (2013) A protocol for better design, application, and communication of population viability analyses. Conservation Biology, 27, 644-656.

Reed, D.H., O'Grady, J.J., Brook, B.W., Ballou, J.D., Frankham, R. (2003) Estimates of minimum viable population sizes for vertebrates and factors influencing those estimates. Biological Conservation, 113, 23-34.

Reed, J.M., Mills, L.S., Dunning, JR, J.B., Menges, E.S., McKelvey, K.S., FrYE, R. et al. (2002) Emerging issues in population viability analysis. Conservation Biology, 16, 7-19.

Shaffer, M.L. (1981) Minimum population sizes for species conservation. BioScience, 31, 131-134.

SMN (Servicio Meteorológico Nacional) (2016) Http://www. smn.gob.ar [accessed 15 July 2016].

Stellatelli, O.A., Vega, L.E., Block, C. \& Cruz, F.B. (2013) Effects on the thermoregulatory efficiency of two native lizards as a consequence of the habitat modification by the introduction of the exotic tree Acacia longifolia. Journal of Thermal Biology, 38, 135-142. Stellatelli, O.A., Block, C., Vega, L.E. \& Cruz, F.B. (2015a) Responses of two sympatric sand lizards to exotic forestations in the coastal dunes of Argentina: some implications for conservation. Wildlife Research, 41, 480-489.

Stellatelli, O.A., Block, C., Vega, L.E. \& Cruz, F.B. (2015b) Non-native vegetation induces changes in predation pressure and escape behavior of two sand lizards (Liolaemidae: Liolaemus). Herpetologica, 71, 136-142.

Tischendorf, L. \& FAhrig, L. (2000) On the usage and measurement of landscape connectivity. Oikos, 90, 7-19.

VEGA, L.E. (1997) Reproductive activity and sexual dimorphism of Liolaemus multimaculatus (Sauria: Tropiduridae). Herpetological Journal, 7, 49-53.

VEGA, L.E. (1999) Ecología de saurios arenícolas de las dunas costeras bonaerenses. PhD thesis. Universidad Nacional de Mar del Plata, Mar del Plata, Argentina.

Vega, L.E., Bellagamba, P.J. \& Fitzgerald, L.A. (200o) Long-term effects of anthropogenic habitat disturbance on a lizard assemblage inhabiting coastal dunes in Argentina. Canadian Journal of Zoology, $78,1653-1660$.

\section{Biographical sketches}

The primary research interests of Federico Kacoliris, Melina VELASCO and IGOR BERKUNSKY are conservation biology and management of threatened and endemic animals. CAMiLA KASS, Nicolas Kass and Tomas Martínez Aguirre are interested in the natural history and ecology of native amphibians and reptiles. VERONICA SIMOY is part of a statistics and mathematics team with many years of experience in modelling natural systems. PABLO GRILLI is predominantly interested in wildlife management. DIEGO Di PIET Ro studies spatial ecology and factors affecting the distribution of native reptiles. JOR GE W ILLI A M s' interests include systematics, biogeography and the natural history of herpetological species in Argentina. 